\title{
miR-204-5p promotes apoptosis and inhibits migration of gastric cancer cells by targeting HER-2
}

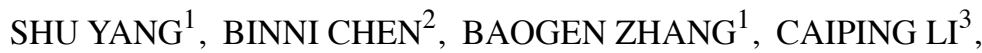 \\ YUENA QIU $^{1}$, HANHUI YANG ${ }^{1}$ and ZHONGXIN HUANG ${ }^{4}$
}

\author{
Departments of ${ }^{1}$ Traditional Chinese Medicine, ${ }^{2}$ Ophthalmology, ${ }^{3}$ Endoscopy Room and ${ }^{4}$ Pathology, \\ The Second Affiliated Hospital of Fujian Medical University, Quanzhou, Fujian 362000, P.R. China
}

Received November 12, 2019; Accepted May 20, 2020

DOI: $10.3892 / \mathrm{mmr} .2020 .11367$

\begin{abstract}
Gastric cancer is one of the most common types of cancer worldwide, with a high incidence and mortality rate. MicroRNAs (miRs) play an important role in tumorigenesis, cell proliferation, migration, apoptosis and metastasis of cancer. The present study aimed to investigate the role and potential mechanism of miR-204-5p in gastric cancer. The mRNA expression levels of miR-204-5p in gastric cancer were determined by reverse transcription-quantitative PCR. Cell proliferation was determined using Cell Counting Kit-8 and colony formation assays. Flow cytometry analysis was performed to detect the cell apoptosis rate. Wound healing and Transwell assays were carried out to determine the cell migration and invasion rates, respectively. A putative binding site of miR-204-5p in the 3' untranslated region of human epidermal growth factor receptor 2 (HER-2) was predicted using a bioinformatics algorithm and confirmed using a dual-luciferase reporter assay. miR-204-5p levels were downregulated in gastric cancer cells. Overexpression of miR-204-5p significantly inhibited cell proliferation and decreased cell colony formation. Additionally, miR-204-5p decreased the migration and invasion rates of gastric cancer cells. Furthermore, an increased apoptotic rate was detected following overexpression of miR-204-5p, along with increased expression levels of Bax and decreased expression levels of Bcl-2. HER-2 was a direct target of miR-204-5p, and inhibition of HER-2 acted as a tumor suppressor by inhibiting cell proliferation, migration and invasion, and promoting cell apoptosis, which was reversed by the inhibition of miR-204-5p expression. These results suggested that miR-204-5p could exert its anti-tumor function by inhibiting cell proliferation, migration and invasion, and
\end{abstract}

Correspondence to: Dr Zhongxin Huang, Department of Pathology, The Second Affiliated Hospital of Fujian Medical University, 34 North Zhongshan Road, Quanzhou, Fujian 362000, P.R. China

E-mail: huangzx158@163.com

Key words: microRNA-204-5p, gastric cancer, human epidermal growth factor receptor 2, apoptosis promoting cell apoptosis via regulation of HER-2, which may be a potential therapeutic target for gastric cancer.

\section{Introduction}

Gastric cancer, one of the most common types of human gastrointestinal cancer, is the second most common cause of cancer-associated death worldwide, with $\sim 720,000$ gastric cancer-related deaths annually $(1,2)$. A national survey assessment reported that the mortality rate of gastric cancer in India is $\leq 12.5 \%$ (3). In East Asia, the burden of gastric cancer is especially high, accounting for $>50 \%$ of gastric cancer incidence $(4,5)$. In China, the 5-year overall survival rate of patients with gastric cancer is $\sim 30 \%$ (6). Furthermore, the overall survival of patients with gastric cancer globally has been continuing to decline since the beginning of the 2000s, with the proportion of gastric cancer patients with metastasis at $\sim 40 \%(3,7-9)$. Currently, the most common treatment methods for gastric cancer are surgical resection, radiotherapy and chemotherapy (10). Most patients with gastric cancer are diagnosed at an advanced stage accompanied by cancer metastasis, and the current therapeutic strategies are limited and have a range of adverse effects, including kidney damage and hair and hearing loss $(11,12)$. Human epidermal growth factor receptor 2 (HER-2), a member of the HER-2 family, is associated with an increased risk of recurrence and poor outcomes of certain malignancies, including breast and gastric cancer (13). HER-2 has been identified to be involved in cancer initiation and progression, and the dysregulation of HER-2 serves as an independent prognostic factor in gastric cancer (14). Thus, HER-2 is a common therapeutic target for gastric cancer.

MicroRNAs (miRNAs/miRs) are a class of non-coding small RNA that consist of 17-25 nucleotides. miRNAs negatively regulate the expression levels of a range of genes by binding to the $3^{\prime}$ untranslated regions (3'UTR) of the mRNA of target genes. miRNAs have been demonstrated to be involved in various physiological and pathological processes, including cancer (15). miRNAs play an important role in tumorigenesis, cell proliferation, migration, apoptosis and metastasis $(16,17)$. miR-204-5p has been identified to be downregulated in several types of cancers, and is a potential regulator in human tumorigenesis $(1,18)$. Based on expression profiling data of gastrointestinal tumor tissues and adjacent 
noncancerous tissues, miR-204-5p is one of the most significantly downregulated miRNAs, and further study suggests that miR-204-5p inhibits gastric cancer cell proliferation, while inhibition of miR-204-5p promotes cell proliferation in gastric cancer $(1,19)$. It has been reported that miRNA-495 interacts with HER-2 to exert its function in gastric cancer; however, whether miR-204-5p also interacts with HER-2 to exert its function remains unclear.

The present study aimed to investigate the function of miR-204-5p and to explore the interaction between miR-204-5p and HER-2, in order to clarify the underlying mechanisms of miR-204-5p and HER-2 in gastric cancer and to provide a valuable therapeutic strategy for gastric cancer treatment.

\section{Materials and methods}

Cell culture. The human normal gastric epithelial HEGC cell and two gastric cancer cell lines, MKN-45 (metastatic gastric cancer cell line derived from a poorly differentiated gastric adenocarcinoma) and AGS (a non-metastatic gastric cancer cell line derived from poorly differentiated gastric adenocarcinoma) were obtained from American Type Culture Collection and cultured in RPMI-1640 medium supplemented with $10 \%$ FBS (Gibco; Thermo Fisher Scientific, Inc.) in a humidified incubator containing $5 \% \mathrm{CO}_{2}$.

Cell transfection. For transfection, MKN-45 cells $\left(5 \times 10^{4}\right.$ cells/well) were plated into 6-well plates and cultured to $90 \%$ confluence. Subsequently, miR-204-5p mimics (5'-UUC CCUUUGUCAUCCUAUGCCU-3'; 50 nM), miR-204-5p inhibitor (5'-AGGCAUAGGAUGACAAAGGGAA-3'; 50 nM), the negative control (5'-UUCUCCGAACGUGUCACGUTT-3'; $50 \mathrm{nM}$ ) and siRNA targeting HER-2 (si-HER-2; 5'-GGUGAA GGUGCUUGGAUCUUU-3'; $500 \mathrm{ng} / \mu \mathrm{l})$ were transfected into cells using Lipofectamine ${ }^{\circledR} 2000$ (Invitrogen; Thermo Fisher Scientific, Inc.), according to the manufacturer's protocol. After $48 \mathrm{~h}$ transfection, transfection efficiency was detected by reverse transcription-quantitative (RT-q) PCR. Subsequent experiments were conducted $48 \mathrm{~h}$ post-transfection.

Cell Counting Kit-8 (CCK-8) assay. Cell viability was measured using a CCK-8 reagent (Dojindo Molecular Technologies, Inc.) according to the manufacturer's instructions. Briefly, MKN-45 cells $\left(5 \times 10^{3}\right.$ cells/well) were cultured in 96-well plates and incubated for $24 \mathrm{~h}$ at $37^{\circ} \mathrm{C}$. Subsequently, CCK-8 reagent ( $10 \mu \mathrm{l} / \mathrm{well})$ was added, and the cells were incubated for another $4 \mathrm{~h}$. Finally, the absorbance of each group at $450 \mathrm{~nm}$ was measured using a microplate reader (Molecular Devices, LLC).

Colony formation assay. After transfection for $24 \mathrm{~h}, \mathrm{MKN}-45$ cells (1,000-1,500 cells/well) were seeded into 6-well plates and incubated for 7 days at $37^{\circ} \mathrm{C}$. During this period, the medium was refreshed every 3 days. Subsequently, cells were fixed with $4 \%$ paraformaldehyde for $15 \mathrm{~min}$ and stained with Giemsa reagent for 10-30 min at room temperature. Finally, colonies were imaged under light microscopy (magnification, $x 100$ ) and the number of colonies ( $\geq 50$ cells/colony) was counted. Three independent experiments were performed for each assay.
Flow cytometry analysis. The rate of cell apoptosis (at early and late phase) was determined using the Apoptosis Detection kit (BD Biosciences) according to the manufacturer's protocol. MKN-45 cells were collected $48 \mathrm{~h}$ post-transfection and resuspended in $500 \mu \mathrm{l}$ binding buffer. Subsequently, MKN-45 cells were incubated with Annexin V-FITC and propidium iodide at room temperature for $15 \mathrm{~min}$ in the dark, and then analyzed using a BD FACSCalibur ${ }^{\mathrm{TM}}$ flow cytometer (BD Biosciences) and BD FACSDiva 6.1.3 software (BD Biosciences).

$R T$ - $q P C R$. Total RNA was extracted from MKN-45 cells using TRIzol $^{\circledR}$ reagent (Thermo Fisher, Scientific, Inc.) according to the manufacturer's instructions. Total RNA was reverse transcribed into cDNA using the PrimeScript RT Master Mix kit (Takara, Bio, Inc.) at $37^{\circ} \mathrm{C}$ for $15 \mathrm{~min}$, followed by an incubation at $85^{\circ} \mathrm{C}$ for $5 \mathrm{sec}$. Determination of gene expression was performed using FastStart Universal SYBR Master Mix (Roche Diagnostics $\mathrm{GmbH}$ ) and analyzed using the $2^{-\Delta \Delta \mathrm{Cq}}$ method (20). The primer sequences were as follows: miR-204-5p forward, 5'-ACACTCCAGCTGGGTTCCCTT TGTCATCCTAT-3' and reverse, 5'-CTCAACTGGTGTCGT GGA-3'; HER-2 forward, 5'-CTGAACTGGTGTATGCAG ATTGC-3' and reverse, 5'-TTCCGAGCGGCCAAGTC-3'; GAPDH forward, 5'-CCATCTTCCAGGAGCGAGAT-3' and reverse, 5'-TGCTGATGATCTTGAGGCTG-3'; U6 forward, 5'-GCTTCGGCAGCACATATACTAAAAT-3' and reverse, 5'-CGCTTCACGAATTTGCGTGTCAT-3'. The thermocycling conditions consisted of an initial denaturation at $95^{\circ} \mathrm{C}$ for $5 \mathrm{~min}$ followed by 40 cycles at $95^{\circ} \mathrm{C}$ for $30 \mathrm{sec}, 60^{\circ} \mathrm{C}$ for $30 \mathrm{sec}$ and $72^{\circ} \mathrm{C}$ for $30 \mathrm{sec}$. GAPDH and U6 served as internal controls for the detection of HER-2 and miRNA, respectively.

Western blotting. Proteins were extracted from MKN-45 cells using radio immunoprecipitation assay protein extraction reagent (Beyotime Institute of Biotechnology) containing $0.5 \mathrm{mM}$ phenylmethanesulfonyl fluoride, and quantified by the Bradford assay. Equal masses of protein sample (30 $\mu \mathrm{g})$ were resolved by SDS-PAGE on a $10 \%$ gel, and subsequently transferred to PVDF membranes. Following blocking in $10 \%$ skimmed milk for $1 \mathrm{~h}$ at room temperature, membranes were incubated at $4{ }^{\circ} \mathrm{C}$ overnight with primary antibodies against $\operatorname{Bax}(1: 1,000$; cat. no. ab182733), Bcl-2 (1:1,000; cat. no. ab196495), HER-2 (1:1,000; cat. no. ab16901) and GAPDH (1:1,000; cat. no. ab181603; all purchased from Abcam). Then, membranes were washed and incubated with the corresponding horseradish peroxidase-conjugated anti-rabbit $(1: 2,000$; cat. no. sc-2004) or anti-mouse $\mathrm{IgG}$ secondary antibodies (1:2,000; cat. no. sc-2005) (both Santa Cruz Biotechnology, Inc.) for $60 \mathrm{~min}$ at room temperature. Protein bands were visualized with ECL Super Signal reagent (Pierce; Thermo Fisher Scientific, Inc.). The relative intensity of the bands was determined using ImageJ software version 1.46 (National Institutes of Health).

Wound healing assay. To determine the migratory ability of cells, cells were grown to $100 \%$ confluence and a scratch was created using a pipette tip. Subsequently, the culture medium was changed to serum-free RPMI-1640 medium and the detached cells were removed. After 24 h, cells were 


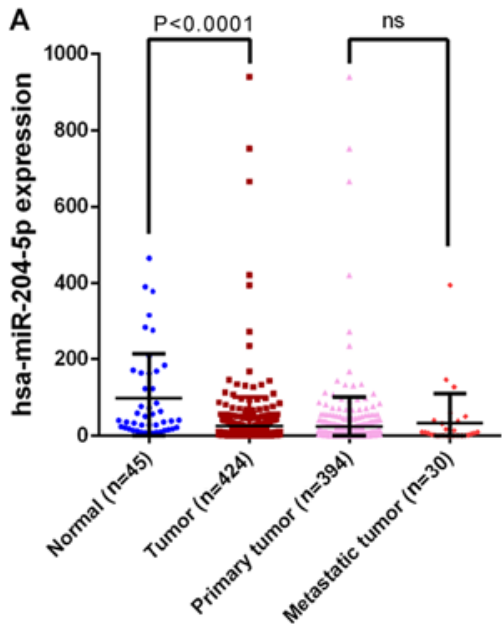

B

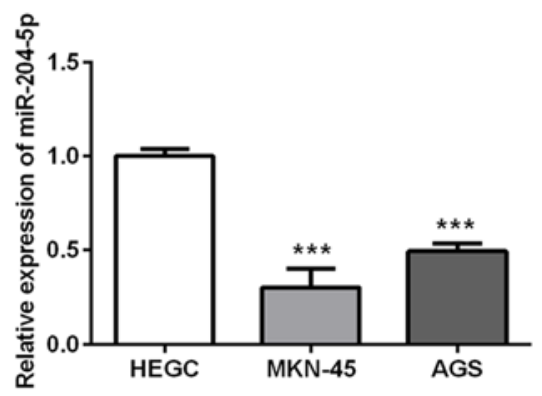

$\mathrm{E}$

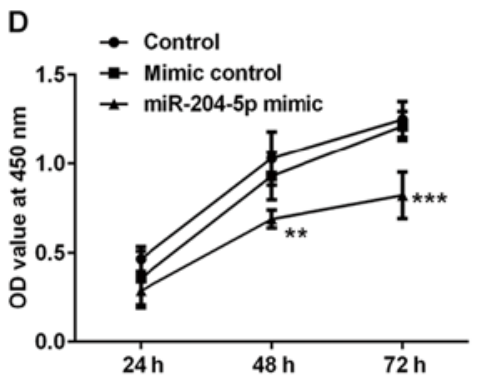

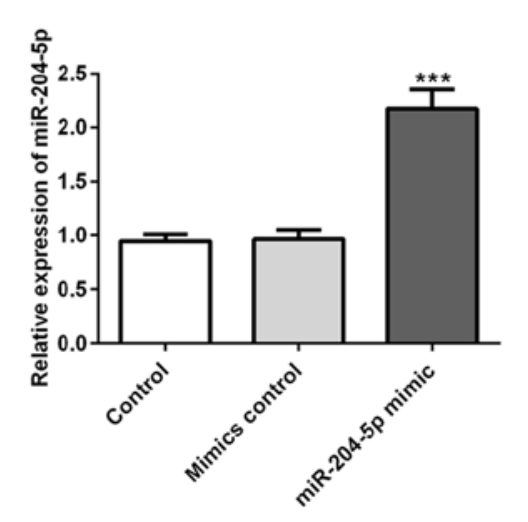

C

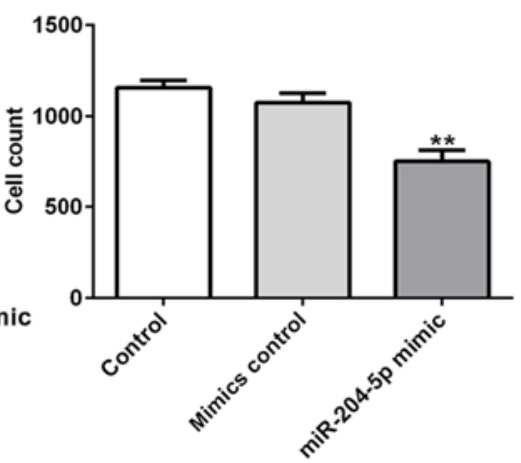

Figure 1. miR-204-5p is downregulated in gastric cancer and inhibits cell proliferation. (A) The Cancer Genome Atlas database was used to identify the association between miR-204-5p and gastric cancer. (B) The mRNA expression levels of miR-204-5p in normal gastric epithelial cell line (HEGC) and gastric cancer cell lines (MKN-45 and AGS) were determined using reverse transcription-quantitative PCR. ${ }^{* * *} \mathrm{P}<0.001$ vs. HEGC cell. (C) MKN-45 cells were transfected with miR-204-5p mimic or mimic control. Cell proliferation was determined using (D) Cell Counting Kit-8 and (E) colony formation assays. ${ }^{* *} \mathrm{P}<0.01$ and ${ }^{* * *} \mathrm{P}<0.001$ vs. mimic control. miR, microRNA.

visualized under a light microscope (magnification, $x 100)$. The cell migration rate was calculated using the following formula: (0 h scratch width-24 h scratch width)/0 h scratch width.

Transwell assay. To determine the invasive ability of cells, $5 \times 10^{4} \mathrm{MKN}-45$ cells were resuspended in $100 \mu \mathrm{l}$ serum-free medium and seeded into the upper Transwell chamber (EMD Millipore), which was pre-coated with Matrigel $^{\mathrm{TM}}$ at room temperature for $25 \mathrm{~min}$. Complete medium supplemented with $10 \%$ FBS was added to the lower chamber. After $24 \mathrm{~h}$, the upper surface of the membrane was wiped with a cotton swab, and the cells attached to the lower surface were fixed with $4 \%$ formaldehyde for $10 \mathrm{~min}$ at room temperature and stained with $0.1 \%$ crystal violet for $10 \mathrm{~min}$ at room temperature. The invasive cells were observed and counted under a light microscope (magnification, x100) from at least five fields. The relative cell invasion rate was calculated using the following formula: Invasive cell count/invasive cell count of control group.

Bioinformatics analysis. The Cancer Genome Atlas (TCGA) database (cancer.gov/tcga) was used to identify the association of miR-204-5p with gastric cancer by collecting the profiles of miR-204-5p in gastric cancer tissues and normal tissues (project no.; TCGA-STAD). The expression of miR-204-5p between normal and tumor tissues or between primary tumor and metastasis tumor tissues was analyzed using the
Wilcoxon-Mann-Whitney test. A putative binding site of miR-204-5p in the 3'UTR of HER-2 was predicted using StarBase (http://starbase.sysu.edu.cn/).

Luciferase reporter assay. HER-2, which contains a putative miR-204-5p binding site, was cloned and inserted into the pmirGLOvector(PromegaCorporation).For the luciferase assay, MKN-45 cells were co-transfected with pmirGLO-HER-2-WT or pmirGLO-HER-2-MUT, and miR-204-5p or negative control using Lipofectamine ${ }^{\circledR}$ (Invitrogen; Thermo Fisher Scientific, Inc.). After $24 \mathrm{~h}$, luciferase activity was measured using the dual luciferase reporter assay system (Promega Corporation). The data were standardized to Renilla luciferase activity.

Statistical analysis. Data are presented as the mean \pm SD of three independent experiments. Data analysis was performed using SPSS software version 17.0 (SPSS, Inc.). Differences between 2 groups were analyzed using the unpaired Student's t-test. Differences among $>2$ groups were analyzed by one-way ANOVA followed by Tukey's post hoc test. $\mathrm{P}<0.05$ was considered to indicate a statistically significant difference.

\section{Results}

miR-204-5p is downregulated in gastric cancer and inhibits cell proliferation. The result from the TCGA analysis 
A
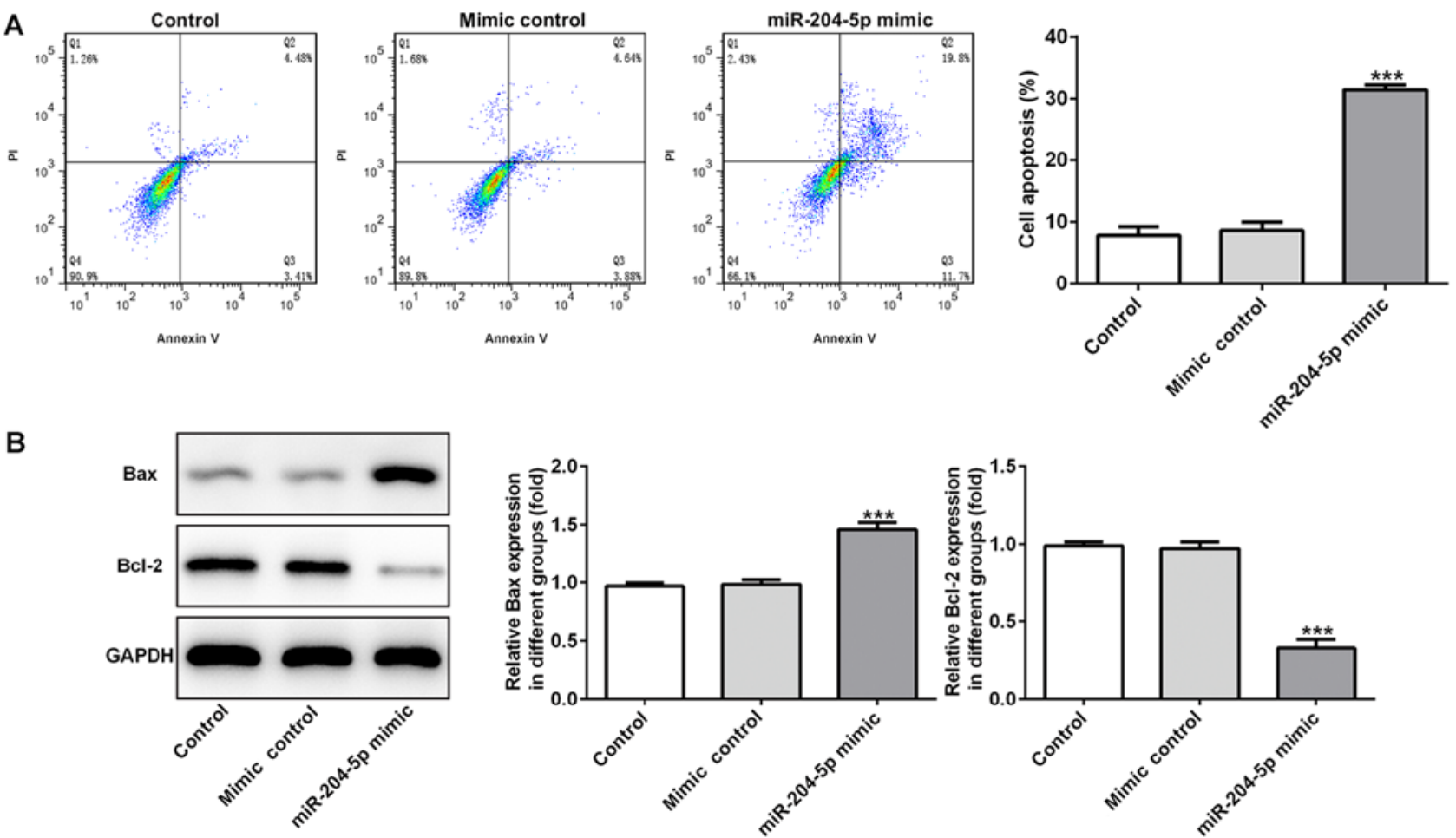

Figure 2. miR-204-5p induces cell apoptosis in gastric cancer. (A) Following transfection, cell apoptosis was determined using flow cytometry. (B) Expression of apoptosis-related proteins (Bax and Bcl-2) was detected using western blotting, and the protein bands were quantified using ImageJ software. ${ }^{* * *} \mathrm{P}<0.001$ vs. mimic control.

revealed a significant lower miR-204-5p expression in gastric cancer tissues than that in normal tissues. Besides, there was no significant difference between the expression level of miR-204-5p in primary and metastatic tumors of patients with gastric cancer (Fig. 1A). To understand the biological function of miR-204-5p in gastric cancer progression, the present study detected miR-204-5p mRNA expression in a normal gastric epithelial cell line (HEGC) and two gastric cancer cell lines (Fig. 1B). The RT-qPCR assay revealed that the expression levels of miR-204-5p were lower in the gastric cancer cell lines, particularly in MKN-45 cells. Therefore, MKN-45 cells were used in subsequent experiments.

First, MKN-45 cells were transfected with miR-204-5p mimics to overexpress miR-204-5p (Fig. 1C). The effect of miR-204-5p on cell proliferation was determined using CCK-8 and colony formation assays. As shown in Fig. 1D and E, the optical density value in the miR-204-5p group was significantly decreased compared with that in the other groups, and the colony numbers in the miR-204-5p mimic group were also decreased, suggesting that overexpression of miR-204-5p could inhibit cell proliferation.

miR-204-5p induces cell apoptosis in gastric cancer. Subsequently, to determine the effect of miR-204-5p on cell apoptosis, flow cytometry analysis was performed and expression levels of apoptosis-related proteins were detected. The flow cytometry results revealed that the apoptotic cell rate was significantly increased when miR-204-5p was overexpressed (Fig. 2A). Bax is a pro-apoptotic protein, whereas Bcl-2 is an anti-apoptotic protein. Increased Bax protein expression and decreased Bcl-2 protein expression were observed in the miR-204-5p mimic group (Fig. 2B), suggesting that overexpression of miR-204-5p could promote MKN-45 cell apoptosis.

miR-204-5p inhibits cell migration and invasion in gastric cancer. To determine the effect of miR-204-5p on cell migration and invasion, wound healing and Transwell assay were performed. As shown in Fig. 3A and B, the size of the wound was decreased after incubation for $24 \mathrm{~h}$, but the wound size in the miR-204-5p mimic group was markedly larger than that in the other groups, suggesting that cells overexpressing miR-204-5p have a decreased migratory ability. Meanwhile, the staining results in Fig. $3 \mathrm{C}$ and $\mathrm{D}$ demonstrated that the number of cells that were attached to the lower surface of the chamber was decreased in the miR-204-5p mimic group, suggesting that the invasive ability was decreased in the miR-204-5p mimic group. Therefore, overexpression of miR-204-5p could suppress cell migration and invasion in gastric cancer.

miR-204-5p directly targets HER-2. Furthermore, the present study examined whether miR-204-5p could directly bind to the 3' UTR of HER-2. miR-204-5p was predicted to target HER-2 using StarBase (Fig. 4A), and the dual-luciferase activity indicated that miR-204-5p could bind to the 3'UTR of HER-2 in MKN-45 cells, thus inhibiting the translation of HER-2 mRNA (Fig. 4B). To further determine the association between miR-204-5p and HER-2, HER-2 expression was detected when miR-204-5p was overexpressed or inhibited. RT-qPCR and western blotting revealed that overexpression of miR-204-5p inhibited the expression of HER-2, whereas 


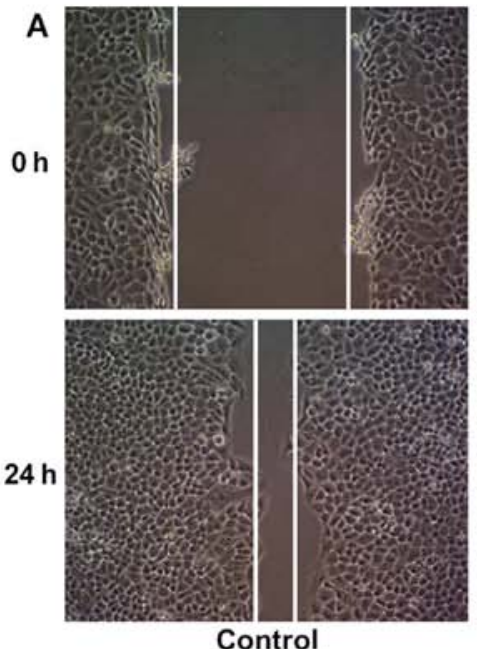

B

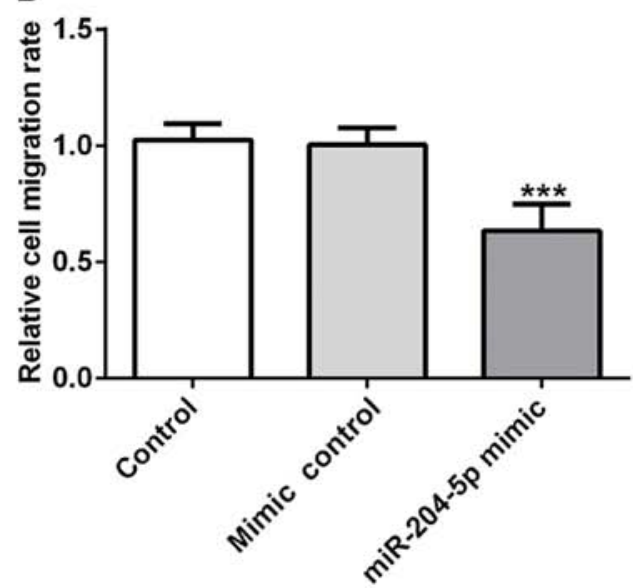

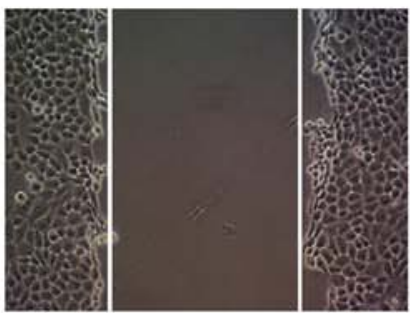

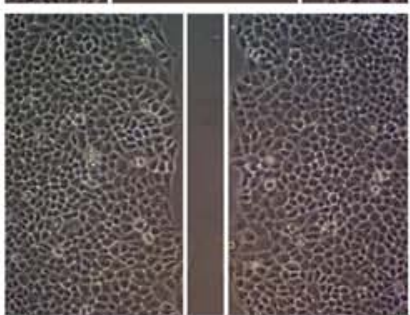

Mimic control
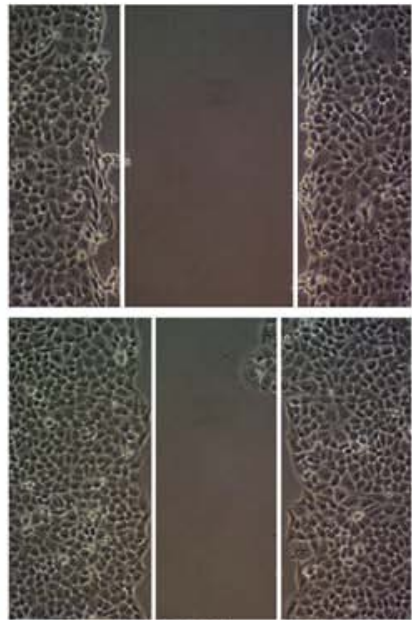

miR-204-5p mimic

D

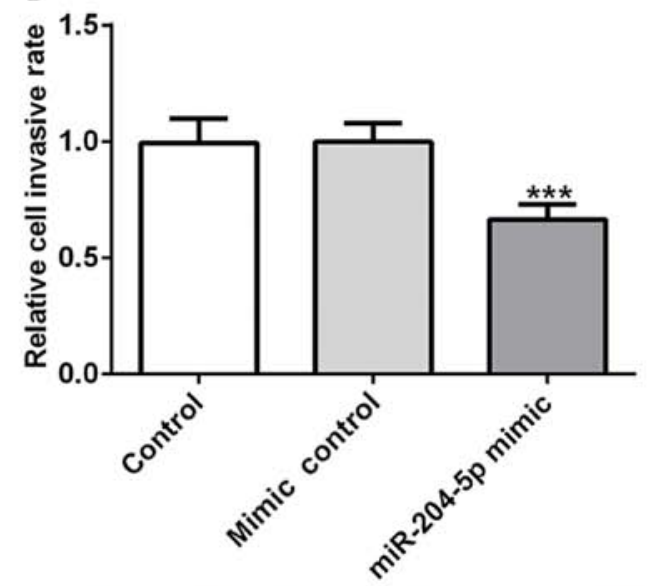

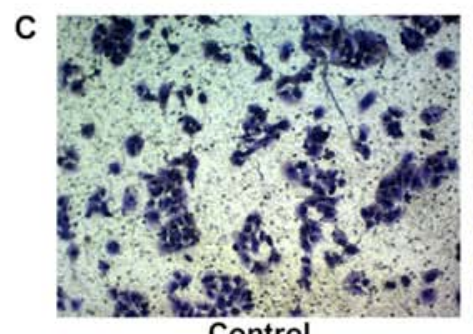

Control

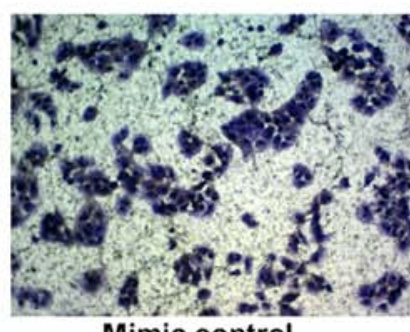

Mimic control

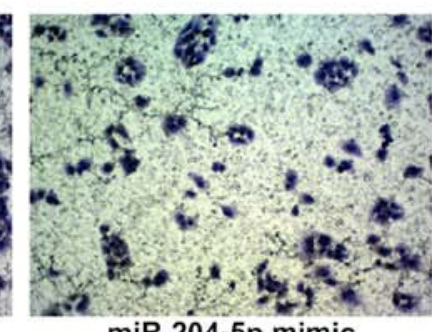

miR-204-5p mimic

Figure 3. miR-204-5p inhibits cell migration and invasion in gastric cancer. (A) Following transfection, cell migration was detected using a wound healing assay; magnification x100. (B) The rate of cell migration was quantified. Cell invasion ability was determined using a (C) Transwell assay; magnification x100. (D) The rate of cell invasion was quantified. ${ }^{* * * *} \mathrm{P}<0.001$ vs. mimic control. miR, microRNA.

downregulation of miR-204-5p increased HER-2 expression in MKN-45 cells (Fig. 4C-E).

miR-204-5p regulates tumorigenesis of gastric cancer by targeting HER-2. To further investigate the interaction between miR-204-5p and HER-2, cells were transfected with si-HER-2 with or without miR-204-5p inhibitor. As shown in Fig. 5A and B, the expression level of HER-2 was significantly decreased when cells were transfected with si-HER-2. In the si-HER-2 group, cell proliferation was significantly inhibited, which was reversed by inhibition of miR-204-5p. The results of the colony formation assay in Fig. 5C and D were consistent with those of the CCK-8 assay. Furthermore, si-HER-2 transfection significantly induced cell apoptosis, which was also reversed by inhibition of miR-204-5p (Fig. 5E). Increased Bax expression and decreased Bcl-2 expression were observed in the si-HER-2 group, which was also reversed by inhibition of miR-204-5p (Fig. 5F), indicating that inhibition of HER-2 induces cell apoptosis via the regulation of $\mathrm{Bax}$ and $\mathrm{Bcl}-2$, and inhibition of miR-204-5p reverses this change by regulating Bax and Bcl-2.

Furthermore, the present study explored the migratory and invasive abilities of gastric cancer cells following the regulation of miR-204-5p and HER-2 expression. The results in Fig. 6A and B showed that inhibition of HER-2 significantly decreased cell migration rate, which was reversed following treatment with miR-204-5p inhibitor. Similarly, results in Fig. 6C and D demonstrated that 


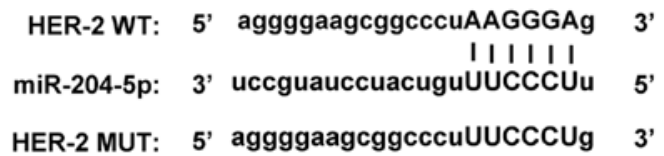

C

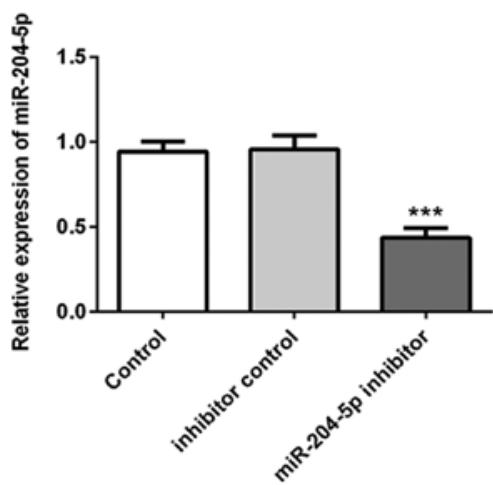

E

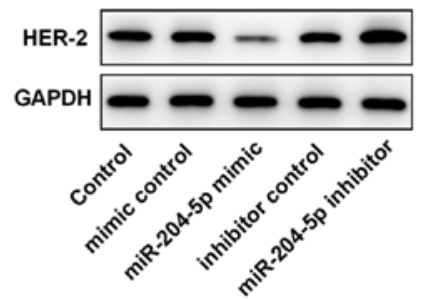

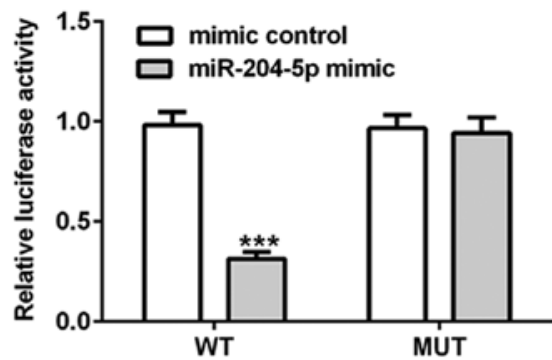
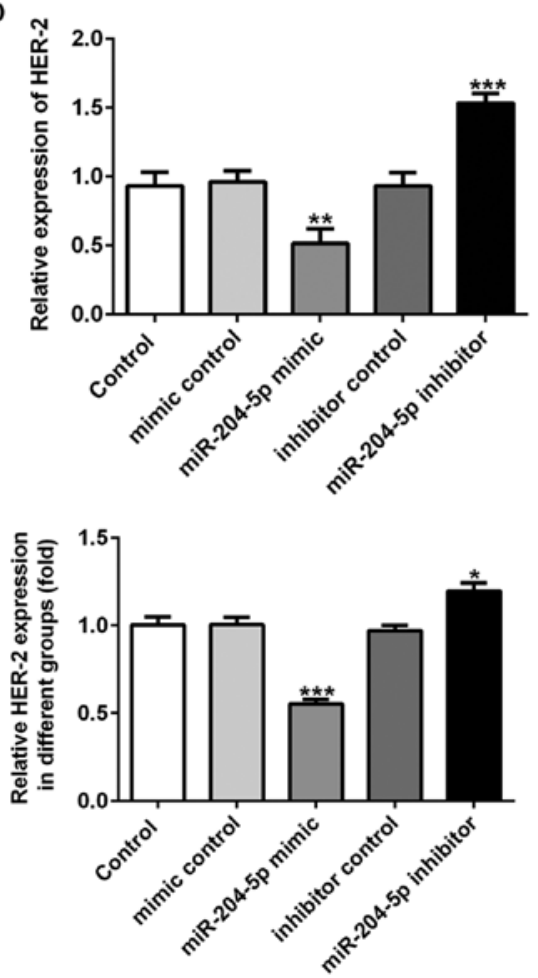

Figure 4. miR-204-5p directly targets HER-2. (A) Data from StarBase showed that miR-204-5p could target HER-2 in MKN-45 cells. (B) Luciferase reporter assay in MKN-45 cells transfected with HER-2 WT or MUT luciferase reporter plasmids, with miR-204-5p mimic or negative control. (C) The transfection efficacy of miR-204-5p in MKN-45 cells was determined using RT-qPCR. (D) RT-qPCR was used to measure the mRNA expression of HER-2 in MKN-45 cells transfected with miR-204-5p mimic or miR-204-5p inhibitor. (E) Western blotting was used to measure the protein expression of HER-2 in MKN-45 cells transfected with miR-204-5p mimic or miR-204-5p inhibitor. ${ }^{*} \mathrm{P}<0.05,{ }^{* *} \mathrm{P}<0.01$ and ${ }^{* * *} \mathrm{P}<0.001$ vs. the control group. miR, microRNA; HER-2, human epidermal growth factor receptor 2; WT, wild-type; MUT, mutant; RT-qPCR, reverse transcription-quantitative PCR.

inhibition of HER-2 significantly suppressed the cell invasion rate, which was reversed following treatment with miR-204-5p inhibitor. The results suggested that inhibition of miR-204-5p could regulate cell migration and invasion by targeting HER-2.

\section{Discussion}

Gastric cancer is one of the most common types of cancer worldwide, with a high incidence rate of $\leq 70 \%$ in developing contrries, particularly in Asia, including China and Korea, as well as parts of South America. At diagnosis, approximately two-thirds of patients with gastric cancer present with local invasion or tumor metastasis $(21,22)$. Therefore, early diagnosis of gastric cancer is critical for effective therapy and prolonging the survival of patients. It has been reported that miRNAs serve an important role during the tumorigenesis and development of gastric cancer (22). Furthermore, an increased number of miRNAs have been demonstrated to have diagnostic and prognostic values in gastric cancer (23). For example, the expression of miR-1246 can be used to differentiate patients with gastric cancer at TNM stage I from healthy controls, indicating that is a potential biomarker for the early diagnosis of gastric cancer (24). miR-381 has a higher sensitivity and specificity in the diagnosis of gastric cancer compared with other miRNAs. Furthermore, downregulated miR-381 has been identified to be positively associated with lymph node metastasis and development of gastric cancer, suggesting the use of miR-381 as a biomarker for early diagnosis in gastric cancer (25). miR-204-5p has been reported to be downregulated and to act as a tumor suppressor in a range of cancer types, such as colorectal cancer, papillary thyroid cancer, malignant melanoma and hepatocellular cancer $(18,26-28)$. It has been demonstrated that miR-204-5p expression is downregulated in gastric cancer tissues, and inhibition of miR-204-5p could suppress cell proliferation by regulating ubiquitin-specific protease 47 and Ras-related protein Rab-22A in gastric cancer cells (1). Based on the 
A

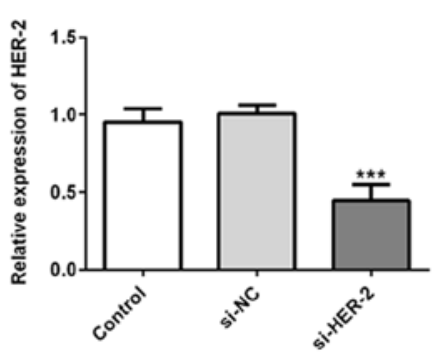

B

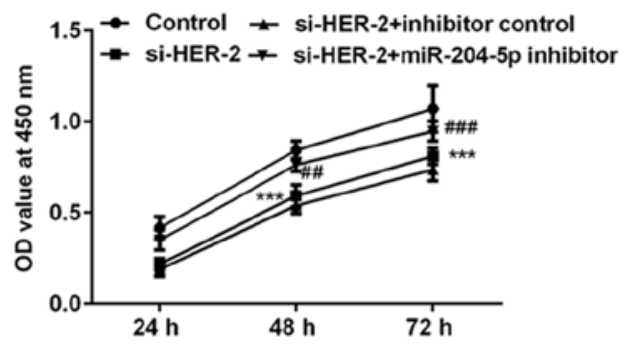

C
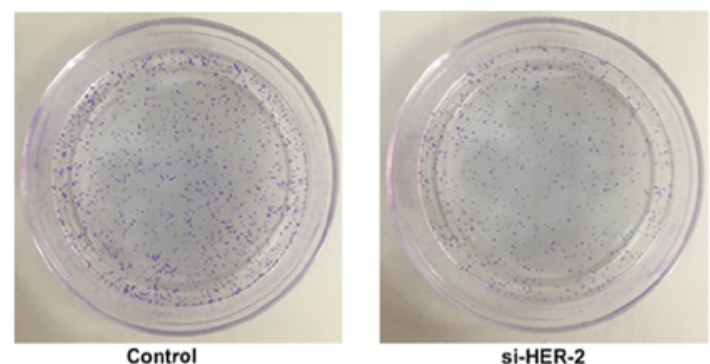

si-HER-2

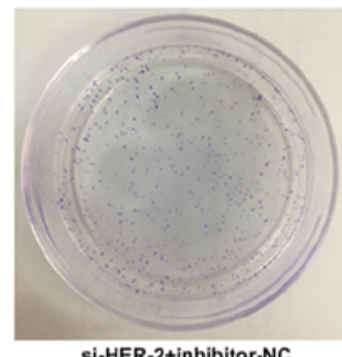

si-HER-2+inhibitor-NC
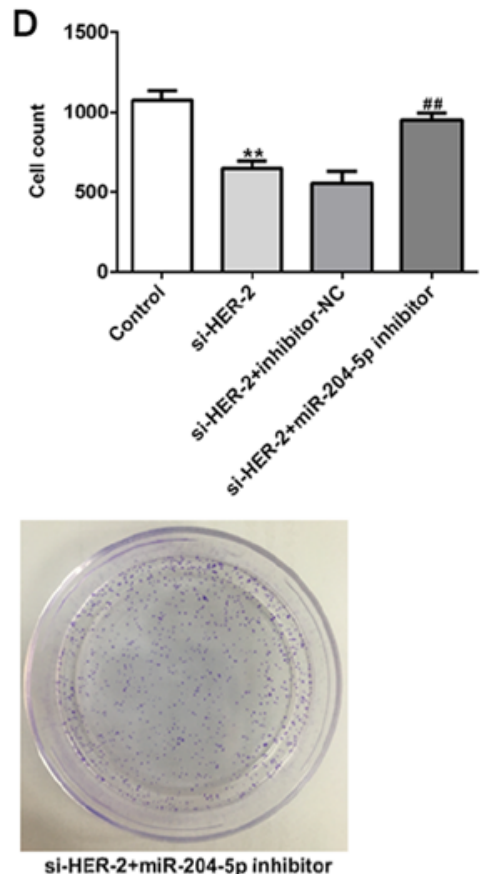

E
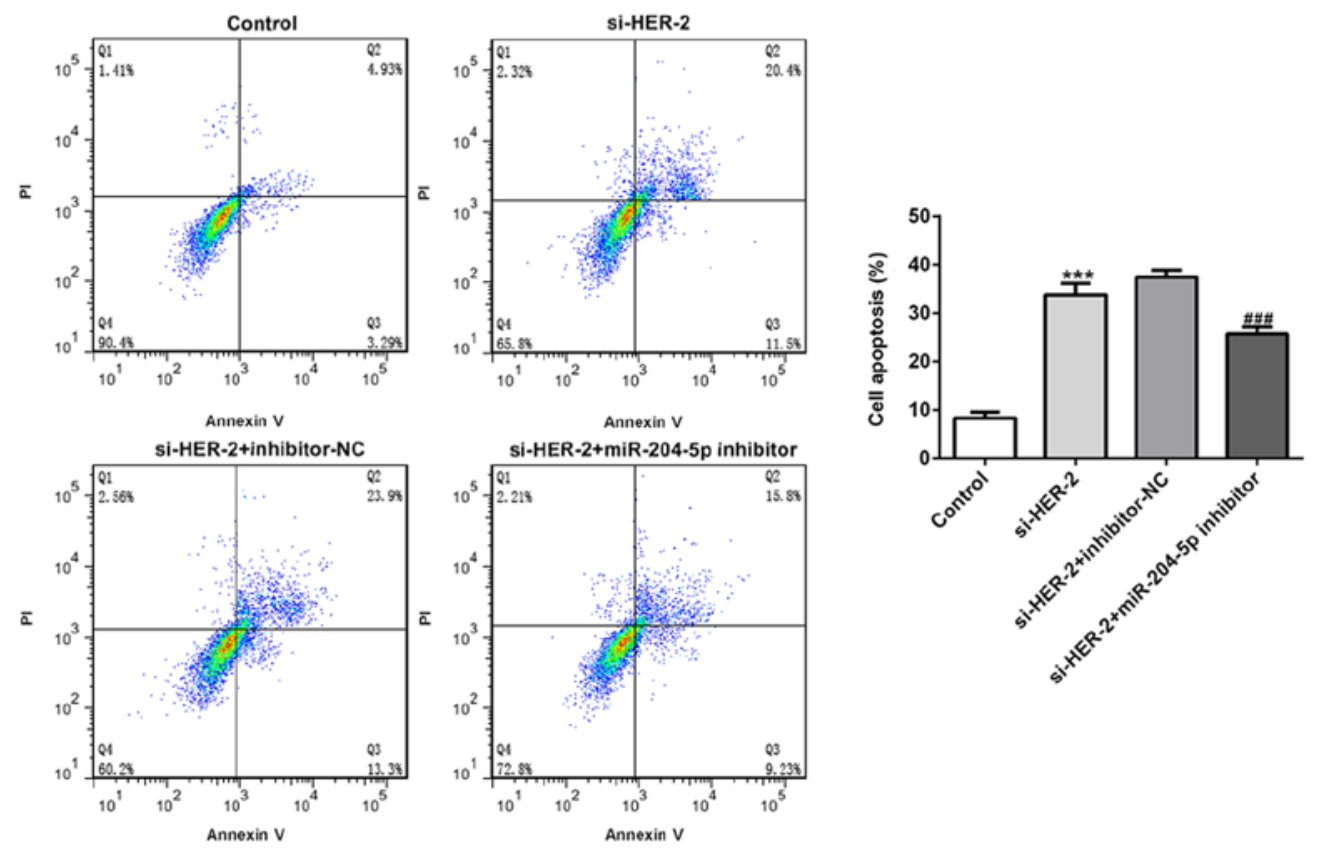

$\mathbf{F}$
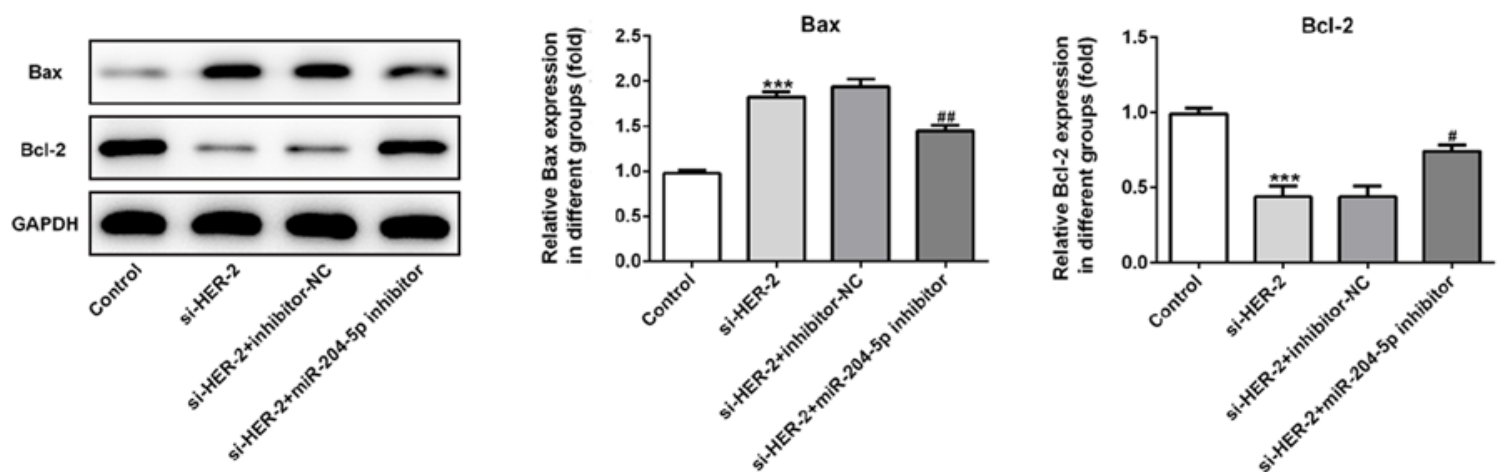

Figure 5. miR-204-5p regulates cell proliferation and apoptosis by targeting HER-2. MKN-45 cells were transfected with si-HER-2 with or without miR-204-5p inhibitor. (A) The transfection efficacy of si-HER-2 in MKN-45 cells was determined using reverse transcription-quantitative PCR. ${ }^{* * * *} \mathrm{P}<0.001$ vs. si-NC Proliferative ability of MKN-45 cells was determined using (B) Cell Counting Kit-8 and (C and D) colony formation assays. (E) Flow cytometry was used to measure cell apoptosis in each group. (F) Western blotting was used to determine protein expression of Bax and Bcl-2, and the protein bands were quantified. ${ }^{* *} \mathrm{P}<0.01$ and ${ }^{* * *} \mathrm{P}<0.001$ vs. control; ${ }^{*} \mathrm{P}<0.05,{ }^{\# \#} \mathrm{P}<0.01$ and ${ }^{\# \# \#} \mathrm{P}<0.001$ vs. si-HER-2 + inhibitor-NC. si, small interfering RNA; HER-2, human epidermal growth factor receptor 2; miR, microRNA; NC, negative control. 

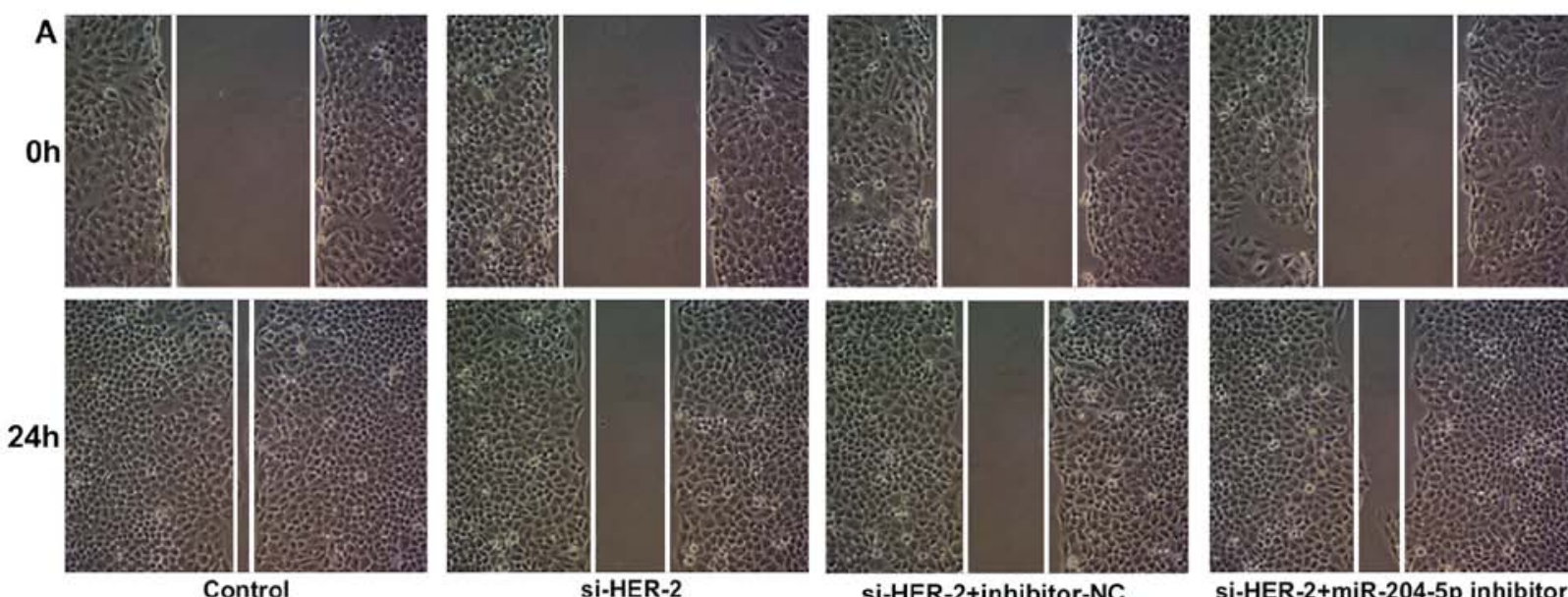

si-HER-2+inhibitor-NC

si-HER-2+miR-204-5p inhibitor

B

D
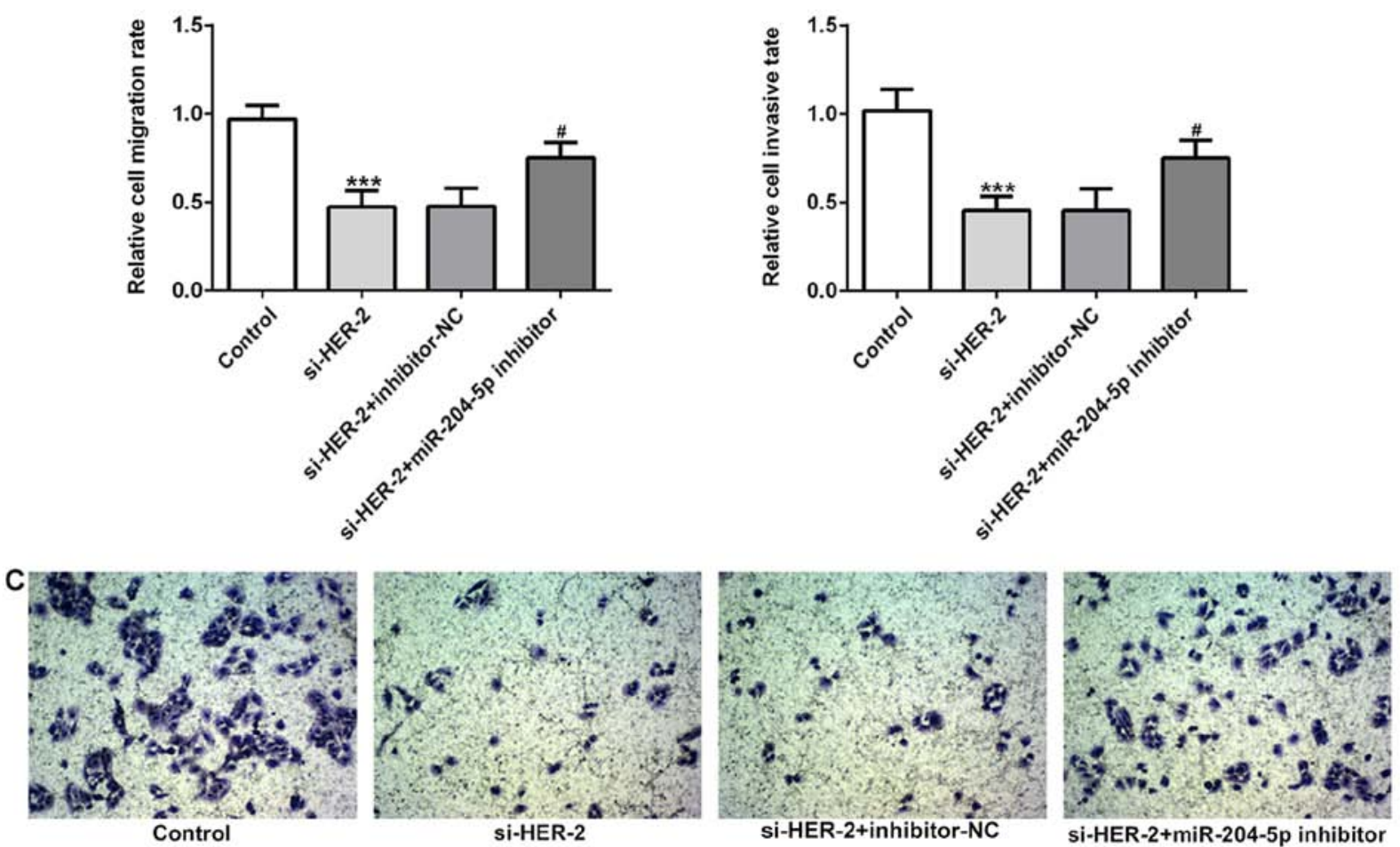

si-HER-2+miR-204-5p inhibitor

Figure 6. miR-204-5p regulates cell migration and invasion by targeting HER-2. (A) Cell migratory ability was detected using a wound healing assay; magnification $\times 100$. (B) The rate of migration was quantified. (C) Cell invasion ability was determined using Transwell assay; magnification x100. (D) The rate of invasion was quantified. ${ }^{* * * *} \mathrm{P}<0.001$ vs. control; ${ }^{*} \mathrm{P}<0.05$ vs. si-HER-2 + inhibitor NC. si, small interfering RNA; HER-2, human epidermal growth factor receptor 2; miR, microRNA; $\mathrm{NC}$, negative control.

current study that investigated miR-204-5p in gastric cancer, the various functions of miR-204-5p and its underlying mechanism of action remain to be explored in further detail to help us understand the role of miR-204-5p in the tumorigenesis and development of gastric cancer, and to provide a more precise diagnostic value for clinical application.

To evaluate the effect of miR-204-5p on the biological characteristics of gastric cancer, the present study overexpressed miR-204-5p in gastric cancer cells. The present study explored the potential mechanism underlying the suppressive effect of miR-204-5p in gastric cancer. Following overexpression of miR-204-5p, the proliferation, migration, invasion and apoptosis rates of cells were detected, and the molecular mechanism was analyzed. In addition to the suppressive effect on cell proliferation in gastric cancer, which was reported in a previous study (19), miR-204-5p also significantly suppressed cell migration and invasion, and promoted cell apoptosis in gastric cancer. The rapid proliferation, migration and invasion of gastric cancer cells is an important reason for tumor metastasis, thus contributing to the development of cancer. The inhibitory effect of miR-204-5p on proliferation, migration and invasion of gastric cancer cells could be an effective strategy for cancer treatment. Apoptosis is an important target for therapeutic intervention in cancer. The Bcl-2 family 
proteins, such as pro-apoptotic protein Bax and anti-apoptotic protein Bcl-2, play critical roles in the regulation of apoptosis of gastric cancer cells $(29,30)$. In the present study, miR-204-5p could promote cell apoptosis of gastric cancer cells by regulating the expression levels of $\mathrm{Bax}$ and $\mathrm{Bcl}-2$, indicating that miR-204-5p is a promising target for inhibiting gastric cancer metastasis.

Recently, studies have focused on the molecular mechanism of miR-204-5p in the regulation of gastric cancer progression, it was demonstrated that miR-204-5p could bind to the 3'UTR of its target genes, such as epidermal growth factor receptor, $\mathrm{CXC}-\mathrm{C}-\mathrm{X}-\mathrm{C}$ motif chemokine receptor 4 and its ligand $\mathrm{C}-\mathrm{X}-\mathrm{C}$ motif chemokine ligand 12 to influence the expression of these genes, thus regulating the progression of gastric cancer $(31,32)$. In the present study, HER-2 was demonstrated to be a direct target of miR-204-5p, and miR-204-5p exhibited suppressive effects on the progression of gastric cancer by inhibiting cell proliferation, migration and invasion, and promoted cell apoptosis by regulating HER-2. HER-2 (also known as ERBB-2), is a proto-oncogene that encodes a $185 \mathrm{kDa}$ plasma membrane-bound tyrosine kinase receptor, located on chromosome 17 at q21 $(33,34)$. mRNA and protein expression levels of HER-2 are upregulated in several types of cancers, therefore it is considered to be a factor associated with poor prognosis $(35,36)$. Currently, anti-HER-2 therapy is usually administered after surgery or in the neoadjuvant setting in breast cancer and gastric cancer $(37,38)$. Inhibition of HER-2 is an effective and promising target in cancer research. Increasing evidence has demonstrated that HER-2 is a direct target of several miRNAs, and miRNAs can regulate cancer progression by inhibiting HER-2 expression. For example, miR-9 targets HER-2 to increase responsiveness of breast cancer cells to cyclophosphamide or docetaxel treatment (39). miR-4319 suppresses growth and increases apoptosis of prostate cancer cells via inhibition of HER-2 (40). In the present study, it was demonstrated that HER-2 was a direct target of miR-204-5p, and miR-204-5p inhibited the protein expression of HER-2. Further experiments revealed that miR-204-5p or inhibition of HER-2 inhibited proliferation, migration and invasion, and promoted apoptosis in gastric cancer cells. Furthermore, the suppressive effect of miR-204-5p on gastric cancer cells was associated with the inhibition of HER-2 expression.

However, the present study still had some limitations. First, the experiments in this study were conducted at the cellular level, therefore it would be useful to study mouse models and patients with gastric cancer to corroborate these in vitro findings. For example, whether miR-204-5p is an effective biomarker to indicate prognosis in patients with gastric cancer needs to be investigated in clinical settings. Additionally, the therapeutic effect of miR-204-5p in gastric cancer needs to be verified in a mouse model. Secondly, the gastric cancer cell lines used in the present study were limited, the role of miR-204-5p expression was only investigated in MKN-45 cells, and further data concerning the role of miR-204-5p in gastric cancer should be obtained from multiple gastric cancer cell lines. Thirdly, the bioinformatics analysis in the present study is also limited. It would be useful to perform analysis using multiple online databases to learn more about the role and effect of miR-204-5p in gastric cancer, and other types of cancer. Our future work will focus on resolving these limitations to gain an increased understanding of the role of miR-204-5p in gastric cancer.

In conclusion, the present study revealed a direct interaction between miR-204-5p and HER-2 in gastric cancer. miR-204-5p exhibited suppressive effects on the progression of gastric cancer via the inhibition of cell proliferation, migration and invasion, and promoted cell apoptosis by regulating HER-2. The data presented in the current study suggest that miR-204-5p and HER-2 could be potential targets for the development of treatments for gastric cancer.

\section{Acknowledgements}

Not applicable.

\section{Funding}

The present study was supported by the Traditional Chinese Medicine Science and Technology of Fujian (grant no. 2017FJZYLC502).

\section{Availability of data and materials}

All data generated or analyzed during this study are included in this published article or available from The Cancer genome Atlas (cancer.gov/tcga) under project no. TCGA-STAD.

\section{Authors' contributions}

ZH and SY contributed to the study design. BC, BZ, CL, YQ and $\mathrm{HY}$ conducted the experiments and performed data analysis. $\mathrm{SY}$ and BC wrote the manuscript. $\mathrm{ZH}$ revised the manuscript and gave the final approval of the version to be submitted. All authors contributed to data analysis, drafting and revising the manuscript and agreed to be accountable for all aspects of the work. All authors read and approved the final manuscript.

\section{Ethics approval and consent to participate}

Not applicable.

\section{Patient consent for publication}

Not applicable.

\section{Competing interests}

The authors declare that they have no competing interests.

\section{References}

1. Zhang B, Yin Y, Hu Y, Zhang J, Bian Z, Song M, Hua D and Huang Z: MicroRNA-204-5p inhibits gastric cancer cell proliferation by downregulating USP47 and RAB22A. Med Oncol 32: 331,2015 .

2. Torre LA, Bray F, Siegel RL, Ferlay J, Lortet-Tieulent J and Jemal A: Global cancer statistics, 2012. CA Cancer J Clin 65: 87-108, 2015

3. Sheikh IA, Mirza Z, Ali A, Aliev G and Ashraf GM: A proteomics based approach for the identification of gastric cancer related markers. Curr Pharm Des 22: 804-811, 2016.

4. Siegel RL, Miller KD and Jemal A: Cancer statistics, 2018. CA Cancer J Clin 68: 7-30, 2018. 
5. Bray F, Ferlay J, Soerjomataram I, Siegel RL, Torre LA and Jemal A: Global cancer statistics 2018: GLOBOCAN estimates of incidence and mortality worldwide for 36 cancers in 185 countries. CA Cancer J Clin 68: 394-424, 2018.

6. Allemani C, Weir HK, Carreira H, Harewood R, Spika D, Wang XS, Bannon F, Ahn JV, Johnson CJ, Bonaventure A, et al: Global surveillance of cancer survival 1995-2009: Analysis of individual data for $25,676,887$ patients from 279 population-based registries in 67 countries (CONCORD-2). Lancet 385 977-1010, 2015.

7. Hundahl SA: Staging, stage migration, and patterns of spread in gastric cancer. Semin Radiat Oncol 12: 141-149, 2002.

8. Thomassen I, van Gestel YR, van Ramshorst B, Luyer MD, Bosscha K, Nienhuijs SW, Lemmens VE and de Hingh IH: Peritoneal carcinomatosis of gastric origin: A population-based study on incidence, survival and risk factors. Int J Cancer 134 622-628, 2014.

9. Tan MC, Balakrishnan M and Graham DY: Gastric cancer worldwide except Japan. In: Gastric Cancer. Shiotani A (ed). Springer, Singapore, pp 17-28, 2019.

10. Song H, Zhu J and Lu D: Molecular-targeted first-line therapy for advanced gastric cancer. Cochrane Database Syst Rev 7: CD011461, 2016

11. Ohno T, Yokoyama Y, Aihara R, Mochiki E, Asao T and Kuwano H: Sudden bilateral sensorineural hearing loss as the presenting symptom of meningeal carcinomatosis of gastric cancer: Report of a case. Surg Today 40: 561-565, 2010.

12. Jansen EP, Saunders MP, Boot H, Oppedijk V, Dubbelman R, Porritt B, Cats A, Stroom J, Olmos RV, Bartelink H and Verheij M: Prospective study on late renal toxicity following postoperative chemoradiotherapy in gastric cancer. Int J Radiat Oncol Biol Phys 67: 781-785, 2007.

13. Boku N: HER2-positive gastric cancer. Gastric Cancer 17: 1-12, 2014.

14. Kepil N, Batur S, Sonmez Wetherilt C and Erdamar Cetin S Human epidermal growth factor receptor 2 (HER-2) status evaluation in advanced gastric cancer using immunohistochemistry versus silver in situ hybridization. Bosn J Basic Med Sci 17: 109-113, 2017.

15. Mishra S, Yadav T and Rani V: Exploring miRNA based approaches in cancer diagnostics and therapeutics. Crit Rev Oncol Hematol 98: 12-23, 2016.

16. Yu J, Feng J, Zhi X, Tang J, Li Z, Xu Y, Yang L, Hu Z and Xu Z: Let-7b inhibits cell proliferation, migration, and invasion through targeting Cthrc1 in gastric cancer. Tumour Biol 36: 3221-3229, 2015.

17. Zhu ED, Li N, Li BS, Li W, Zhang WJ, Mao XH, Guo G, Zou QM and Xiao B: miR-30b, down-regulated in gastric cancer, promotes apoptosis and suppresses tumor growth by targeting plasminogen activator inhibitor-1. PLoS One 9: e106049, 2014

18. Yin Y, Zhang B, Wang W, Fei B, Quan C, Zhang J, Song M, Bian Z, Wang Q, Ni S, et al: miR-204-5p inhibits proliferation and invasion and enhances chemotherapeutic sensitivity of colorectal cancer cells by downregulating RAB22A. Clin Cancer Res 20: 6187-6199, 2014.

19. Liang $Y$, Zhang CD, Zhang $C$ and Dai DQ DLX6-AS1/miR-204-5p/OCT1 positive feedback loop promotes tumor progression and epithelial-mesenchymal transition in gastric cancer. Gastric Cancer 23: 212-227, 2020.

20. Livak KJ and Schmittgen TD: Analysis of relative gene expression data using real-time quantitative PCR and the 2(-Delta Delta C(T)) method. Methods 25: 402-408, 2001.

21. Jemal A, Bray F, Center MM, Ferlay J, Ward E and Forman D: Global cancer statistics. CA Cancer J Clin 61: 69-90, 2011.

22. Wang QX, Zhu YQ, Zhang $\mathrm{H}$ and Xiao J: Altered miRNA expression in gastric cancer: A systematic review and meta-analysis. Cell Physiol Biochem 35: 933-944, 2015.

23. Shin VY and Chu KM: MiRNA as potential biomarkers and therapeutic targets for gastric cancer. World J Gastroenterol 20: 10432-10439, 2014.
24. Shi Y, Wang Z, Zhu X, Chen L, Ma Y, Wang J, Yang X and Liu Z Exosomal miR-1246 in serum as a potential biomarker for early diagnosis of gastric cancer. Int J Clin Oncol 25: 89-99, 2020.

25. Li Y, Sun H, Guan J, Ji T and Wang X: Serum microRNA-381: A potential marker for early diagnosis of gastric cancer. Yonsei Med J 60: 720-726, 2019.

26. Liu L, Wang J, Li X, Ma J, Shi C, Zhu H, Xi Q, Zhang J, Zhao X and $\mathrm{Gu} \mathrm{M}$ : miR-204-5p suppresses cell proliferation by inhibiting IGFBP5 in papillary thyroid carcinoma. Biochem Biophys Res Commun 457: 621-626, 2015.

27. Luan W, Qian Y, Ni X, Bu X, Xia Y, Wang J, Ruan H, Ma S and $\mathrm{Xu}$ B: miR-204-5p acts as a tumor suppressor by targeting matrix metalloproteinases-9 and B-cell lymphoma-2 in malignant melanoma. Onco Targets Ther 10: 1237-1246, 2017.

28. Chu Y, Jiang M, Du F, Chen D, Ye T, Xu B, Li X, Wang W, Qiu Z, Liu H, et al: miR-204-5p suppresses hepatocellular cancer proliferation by regulating homeoprotein SIX1 expression. FEBS Open Bio 8: 189-200, 2018

29. Jia X, Wen Z, Sun Q, Zhao X, Yang H, Shi X and Xin T: Apatinib suppresses the proliferation and apoptosis of gastric cancer cells via the PI3K/Akt signaling pathway. J BUON 24: 1985-1991, 2019.

30. Shang HS, Lu HF, Lee CH, Chiang HS, Chu YL, Chen A, Lin YF and Chung JG: Quercetin induced cell apoptosis and altered gene expression in AGS human gastric cancer cells. Environ Toxicol 33: 1168-1181, 2018.

31. Zhang J, Xing L, Xu H, Wang K, She J, Shi F, Wu H, Sun Y, Gao J and He S: miR-204-5p suppress lymph node metastasis via regulating CXCL12 and CXCR4 in gastric cancer. J Cancer 11: 3199-3206, 2020

32. Wang Y, Zhang H, Ge S, Fan Q, Zhou L, Li H, Bai M, Ning T, Liu R, Wang X, et al: Effects of miR1385p and miR2045p on the migration and proliferation of gastric cancer cells by targeting EGFR. Oncol Rep 39: 2624-2634, 2018.

33. Slamon DJ, Godolphin W, Jones LA, Holt JA, Wong SG, Keith DE, Levin WJ, Stuart SG, Udove J and Ullrich A: Studies of the HER-2/neu proto-oncogene in human breast and ovarian cancer. Science 244: 707-712, 1989.

34. Fanotto V, Ongaro E, Rihawi K, Avallone A, Silvestris N, Fornaro L, Vasile E, Antonuzzo L, Leone F, Rosati G, et al: HER-2 inhibition in gastric and colorectal cancers: Tangible achievements, novel acquisitions and future perspectives. Oncotarget 7: 69060-69074, 2016.

35. Begnami MD, Fukuda E, Fregnani JH, Nonogaki S, Montagnini AL, da Costa WL Jr and Soares FA: Prognostic implications of altered human epidermal growth factor receptors (HERs) in gastric carcinomas: HER 2 and HER3 are predictors of poor outcome. J Clin Oncol 29: 3030-3036, 2011.

36. Di Oto E, Brandes AA, Cucchi MC and Foschini MP: Prognostic impact of HER-2 Subclonal Amplification in breast cancer. Virchows Arch 471: 313-319, 2017.

37. Oke OW and Carla L; Gregor, Mariana Chavez-Mac: Outcomes related to delayed initiation of anti-HER 2 therapy in pregnant HER 2 positive breast cancer patients. 53rd Annual Meeting of the American-Society-of-Clinical-Oncology (ASCO). 2017.

38. Shabbir A, Qureshi MA, Mirza T and Khalid AB: Human epidermal growth factor (Her-2) in gastric and colorectal adenocarcinoma. J Pak Med Assoc 67: 1085-1090, 2017.

39. Sun G, Sun L, Liu Y, Xing H and Wang K: Her-2 expression regulated by downregulation of miR-9 and which affects chemotherapeutic effect in breast cancer. Cancer Gene Ther 24 194-202, 2017.

40. Zhao D, Sui Y and Zheng X: miR-331-3p inhibits proliferation and promotes apoptosis by targeting HER2 through the PI3K/Akt and ERK1/2 pathways in colorectal cancer. Oncol Rep 35: 1075-1082, 2016.

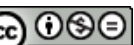

This work is licensed under a Creative Commons Attribution-NonCommercial-NoDerivatives 4.0 International (CC BY-NC-ND 4.0) License. 